\title{
Serviço Social: profissão e ciência. Contributos para o debate científico nas ciências sociais
}

\author{
Social Work: profession and science. Contributions to the scientific debate \\ in the social sciences
}

\author{
Jorge Manuel LeITÃo FERREIRA \\ ISCTE-Instituto Universitário de Lisboa \\ jorge.manuel.ferreira@iscte.pt
}

Recibido: 02/04/2014

Revisado: 29/05/2014

Aceptado: 19/09/2014

Disponible on line: 10/12/2014

\begin{abstract}
Resumo
No presente artigo procuramos refletir o «Serviço Social» como área de conhecimento das ciências Sociais e Humanas, no quadro da organização do ensino superior de acordo com as orientações da Declaração de Bolonha, tendo por unidade de análise o Serviço Social em Portugal. Abordamos questões inerentes ao debate académico sobre a dimensão científica do Serviço Social no quadro das ciências Sociais, ilustrando alguns marcos significativos de afirmação do Serviço Social português. Refletimos sobre os princípios e valores que devem acompanhar o debate científico do Serviço Social contemporâneo ao nível da investigação, da formação e da profissão. Realçamos a importância do grau de Doutor em Serviço Social no campo académico mas também refletimos sobre as suas consequências na profissão. Terminamos com um conjunto de perspetivas reflexivas sobre o Serviço Social na atualidade, desafiando a academia a formalizar um novo compromisso entre a Universidade e as Organizações Sociais, fortalecendo e valorizando a formação prática através de estágios curriculares supervisionados.
\end{abstract}

Palavras-chave: formação, investigação, princípios, valores, Serviço Social.

\begin{abstract}
This article is intended to reflect the «Social Work» as an area of knowledge of the Social and Human Sciences in the framework of the organization of higher education in accordance with the guidelines of the Bologna Declaration. The unit of analysis is Social Work in Portugal. We address issues related to the academic debate on the scientific dimension of social work within the Social sciences, illustrating some significant affirmation milestones of Portuguese Social Work. We reflect on the principles and values that must accompany the contemporary scientific debate in terms of research, education and social work profession. We emphasize the importance of the Ph. D. degree in Social Work in the academic field but we also reflect on its consequences in the profession. We end up with a set of reflective perspectives on social work today, challenging the academy to formulate a new commitment between the University and the Social Organizations, strengthening and enhancing training through a supervised internship.
\end{abstract}

Keywords: education, research, principles, values, Social Work.

\section{Resumen}

En este artículo se pretende reflejar el Trabajo Social como área de conocimiento de las Ciencias Sociales y Humanas en el marco de la organización de la educación superior de acuerdo con las directrices de la Declaración de Bolonia, con la unidad de análisis de Trabajo Social en Portugal. Nos referimos a las cuestiones relacionadas con el debate académico sobre la dimensión científica de la disciplina, dentro de las ciencias sociales que ilustran algunos hitos significativos de afirmación del Trabajo Social portugués. Reflexionamos sobre los principios y valores que deben acompañar al debate científico contemporáneo como la investigación, la formación y la profesión de trabajo social. Destacamos la importancia del posgrado de Doctor en Trabajo Social en el ámbito académico, también así como la reflexión sobre sus consecuencias en la profesión. Terminamos con un conjunto de perspectivas de reflexión sobre el Trabajo Social en la actualidad, desafiando a la academia para la formalización de un nuevo compromiso entre la Universidad y las organizaciones sociales, el fortalecimiento y la mejora de la formación a través de la práctica supervisada.

Palabras clave: educación, investigación, principios, valores, Trabajo Social.

Referencia normalizada: Leitão Ferreira, J. M. (2014): «Serviço Social: profissão e ciência. Contributos para o debate científico nas ciências sociais». Cuadernos de Trabajo Social 27(2): 329-341.

Sumario: Introduçao. 1. Formação e qualificação em Serviço Social. 2. O debate académico e científico do Serviço Social no quadro das Ciências Sociais. 3. Princípios e valores do Serviço Social contemporâneo. 4. Impactos e dinâmicas profissionais. 5. Conclusões. 6. Referências. 


\section{Introdução}

$\mathrm{O}$ artigo sistematiza um conjunto de análises teóricas e técnicas no domínio do Serviço Social a partir da investigação e de uma reflexão aprofundada sobre o tema, integrada na nova definição de Serviço Social Internacional, aprovada pela IFSW (2014) e levanta um conjunto de questões sobre a formação universitária em Serviço Social no quadro da declaração de Bolonha.

Ao longo deste propomos uma reflexão sobre as mudanças sociais, políticas e económicas ocorridas na última década na sociedade global, interpelando-as com a necessidade de repensar a formação graduada e pós-graduada em Serviço Social numa perspetiva internacional e contextual comprometida com o seu objeto de estudo, por forma a garantir uma prática profissional mais eficiente e eficaz na promoção do bem-estar social e da qualidade de vida do cidadão.

Fazemos ainda um enquadramento da formação em Serviço Social a partir do caso português e refletimos sobre o debate académico nas ciências sociais centrado no Serviço Social como área de conhecimento científico (ciência). Falamos dos princípios e valores do Serviço Social contemporâneo, estabelecendo uma relação com a profissão e procurando identificar os impactos que a formação (graduada e pós-graduada) tem no exercício do assistente social.

Nas conclusões deixamos um conjunto de reflexões e inquietações para debate e aprofundamento do tema.

\section{Formação e qualificação em Serviço So- cial}

A formação em Serviço Social está em Portugal e na maioria dos países europeus estruturada, desde o início do seculo XXI, segundo as orientações da declaração de Bolonha, integrando-se assim num debate igual a todas as ciências sociais no contexto da formação universitária.

Analisando o caso Português, a lei de 2006 do ministério de educação português, referente ao regime jurídico dos graus e diplomas do ensino superior referia a «necessidade de transição de um sistema de ensino baseado na ideia da transmissão de conhecimentos para um sistema baseado no desenvolvimento de competências» (Preâmbulo, DL no 74/2006, de 24 de março). Orientação que levou à estruturação dos planos de estudo em Serviço Social, reduzindo o nú- mero de anos de formação, o número de horas letivas e a diversidade de áreas científicas complementares à formação nuclear (enfraquecendo o perfil de formação interdisciplinar), fragilizando assim a qualidade da formação e preparação do assistente social para o desempenho de uma intervenção mais sustentada numa sociedade mais complexa, caraterizada por conceitos de democracia, cidadania e neoliberalismo. $\mathrm{O}$ modelo de formação mais orientado para as competências conduziu a práticas profissionais mais casuísticas, controladoras e mais centradas em dimensões técnicas-administrativas.

Contudo, a missão do ensino superior fundamenta-se na transmissão de conhecimento, sendo errado desvalorizar ou opô-lo ao conceito de competências:

Todo o sistema de ensino visa a aquisição de conhecimentos pelos estudantes, o que inclui, de forma adequada conforme os níveis, a sua apropriação, sistematização e exploração e a sua operacionalização em contextos diversos, assim como o desenvolvimento correlativo de capacidades e atitudes (Preâmbulo, DL no 115/2013 de 7 de agosto).

Esta orientação do conhecimento assume-se como uma dimensão importante para a formação em Serviço Social na medida que o assistente social tem de ter o domínio macro, ou seja, o conhecimento da sociedade global, compreendendo as mudanças estruturais e conjunturais sofridas na sociedade contemporânea ao nível do aumento da desigualdades sociais, do desemprego, insegurança, redução dos direitos sociais, fragilidade do estado social e a emergência da ressurreição de um velho paradigma e que tem vindo a transformar (de novo) o cidadão em consumidor das prestações sociais, retirando-lhe a dimensão de produtor do seu próprio bem-estar social. Tem de ter o domínio meso, i.e., o conhecimento da organização social atual do Estado e da sociedade civil, a compreensão dos referenciais de política económica resultante de uma corrente neoliberal com impactos significativos na redução do Estado Social e em consequência no enfraquecimento das políticas sociais e da proteção social. E tem de ter ainda um terceiro domínio, micro, que passa pelo conhecimento da realidade social, do contexto sociocultural e familiar e das condições de vida da pessoa. 
Atualmente em Portugal o ensino de Serviço Social contempla os três ciclos de estudo: Licenciatura, Mestrado e Doutoramento e integra-se em quatro contextos institucionais diferenciados: Universidades, Universidade Católica Portuguesa, Institutos Politécnicos e Estabelecimentos de Ensino Superior Particular e Cooperativo.

No que respeita à capacidade reconhecida para atribuição de graus académicos, a lei do ensino superior refere: «no ensino politécnico, são conferidos os graus de licenciado e de mestre. No ensino universitário, são conferidos os graus de licenciado, mestre e doutor» $\left(\mathrm{DL}-\mathrm{n}^{\mathrm{o}}\right.$ 115/2013, art. $^{\circ} 4^{\mathrm{o}}$, de 7 de agosto).

O Decreto-lei $n^{\circ} 115 / 2013$ de 7 de agosto, define no art. $^{\circ} 5^{\circ}$ o que se entende por grau de Licenciado $^{1}$; o art. $^{\circ} 15^{\circ}$ define o que se entende por grau de $\mathrm{Mestre}^{2}$, sendo este «conferido numa especialidade, podendo, quando necessário, as especialidades ser desdobradas em áreas de especialização»; e o art. $^{\circ} 28^{\circ}$ define o que se entende por grau de doutor ${ }^{3}$ e que é «conferido num ramo do conhecimento ou numa sua especialidade».

A formação em Serviço Social ministrada no ensino politécnico conducente ao grau de licenciado
Deve valorizar especialmente a formação que visa o exercício de uma atividade de caráter profissional, assegurando aos estudantes uma componente de aplicação dos conhecimentos e saberes adquiridos às atividades concretas do respetivo perfil profissional» (DL, $\mathrm{n}^{\circ} 115 / 2013$, art. $^{\circ} 8^{\circ}$, de 7 de agosto). A formação ministrada no ensino universitário deve «(...) adotar valores similares aos das instituições de referência de ensino universitário do espaço europeu nas mesmas áreas, tendo em vista assegurar aos estudantes portugueses condições de mobilidade e de formação e de integração profissional semelhantes, em duração e conteúdo, às dos restantes Estados que integram aquele espaço (DL, $\mathrm{n}^{\circ}$ 115/2013, art. ${ }^{\circ}{ }^{\circ}$, de 7 de agosto).

$\mathrm{Na}$ estrutura de ensino superior Português, a formação em Serviço Social ao nível do $1^{\circ}$ ciclo (licenciatura), tem maioritariamente a duração de seis semestres com 180 créditos, verificando-se alguns cursos com a duração de sete semestres com 210 créditos. O $2^{\circ}$ ciclo de estudos conducente ao grau de mestre tem 90 a 120 créditos e uma duração normal de quatro semestres curriculares e alguns cursos têm três semestres. O programa doutoral em Serviço Social tem um ano curricular organizado em dois semestres e

${ }^{1}$ «O grau de Licenciado é conferido aos que demonstrem possuir conhecimentos e capacidade de compreensão numa área de formação:

b) Saber aplicar os conhecimentos e a capacidade de compreensão adquiridos, de forma a evidenciarem uma abordagem profissional ao trabalho desenvolvido na sua área vocacional;

c) Capacidade de resolução de problemas no âmbito da sua área de formação (...) e argumentação;

d) Capacidade de recolher, selecionar e interpretar a informação relevante (...), incluindo na análise os aspetos sociais, científicos e éticos relevantes;

e) Competências que lhe permitam comunicarem informação (...), tanto a públicos constituídos por especialistas como por não especialistas;

f) Competência de aprendizagem que lhes permitam uma aprendizagem ao longo da vida (...)».

2 «O grau de mestre é conferido aos que demonstrem:

b) Saber aplicar os seus conhecimentos e a sua capacidade de compreensão e resolução de problemas em situações novas (...), em contextos alargados e multidisciplinares, (...).

c) Capacidade para integrar conhecimentos, lidar com questões complexas, desenvolver soluções ou emitir juízos em situações de informação (...),

d) Ser capaz de comunicar as suas conclusões e os conhecimentos e raciocínios a elas subjacentes, (...), de forma clara e sem ambiguidades;

e) Competências que lhe permitam uma aprendizagem ao longo da vida, (...)».

3 O grau de doutor é conferido aos que demonstrem:

a) Capacidade de compreensão sistemática num domínio científico de estudo;

b) Competências, aptidões e métodos de investigação associados a um domínio científico;

c) Capacidade para conceber, projetar, adaptar e realizar uma investigação significativa (...);

d) Ter realizado um conjunto significativo de trabalhos de investigação original que tenha contribuído para o alargamento das fronteiras do conhecimento, (...);

g) Ser capaz de, numa sociedade baseada no conhecimento, promover em contexto académico e ou profissional, o progresso tecnológico, social ou cultural. 
dois anos (podendo ser prorrogado por mais um ano) de elaboração de uma tese original adequada à natureza do ramo de conhecimento ou da especialidade.

O Serviço Social tem os seus fundamentos científicos no quadro das ciências sociais e humanas e os seus fundamentos éticos nas questões dos direitos humanos, da dignidade humana, da justiça social e da autodeterminação do sujeito como pessoa/cidadão.

A partir dos anos oitenta com a adesão de Portugal à União Europeia (1986), a construção do conhecimento em Serviço Social ganhou novos desafios no quadro da mundialização e globalização da sociedade e do saber. O Serviço Social Português passou a estabelecer um dialogo de proximidade com entidades congeneres dos diferentes paises da então Comunidade Económica Europeia, passando a resgatar a produção do conhecimento produzido nos paises AngloSaxónicos, ampliando o seu expectrum teórico e metodológico muito centrado no conhecimento Francófono e da América Latina, tornando os seus planos de estudo mais internacionais e competitivos no espaço europeu e internacional. Foi também influenciado indirectamente pelos principios da Estratégia de Lisboa (2000) e pela Carta Social Europeia. Adotando como pressupostos para o seu desenvolvimento e aprofundamento teórico, os objectivos do conhecimento e competitividade (empreendedorismo e «empowerment»), da coesão social (justiça social e igualdade de género e de oportunidades) e da economia sustentável baseada no desenvolvimento social e humano (partenariado e interdisciplinaridade).

$\mathrm{Na}$ atualidade a União Europeia nas suas diferentes instituições reconhece no Serviço Social uma ação privilegiada para a coesão social, requerendo no domínio científico da formação e da investigação o aprofundamento das dimensões teóricas e científicas. No âmbito da intervenção do assistente social exige-se, uma intervenção profissional sustentada em procedimentos teóricos e metodológicos (conhecimento/saber) e em princípios ético-deontológicos, reconhecendo o sujeito como parceiro na ação (sujeito/cidadão). Dimensões que interpelam a academia e a profissão sobre o aprofundamento do conhecimento desta área do conhecimento que responda com eficiência e eficácia a modelos sociais de intervenção que incluem a pessoa, a formação de um profissional que influencie uma política mais humanitária e que promova novos métodos que produzam resultados de melhoria de vida das pessoas integradas na sociedade civil e que inove na prática do assistente social a aplicação dos direitos humanos promotor de novos modelos de intervenção profissional.

Os modelos de bem-estar social ao nível europeu, com particular ênfase no caso português, possibilitam ao assistente social um melhor enquadramento das suas atribuições, funções e uma melhor perceção do contexto social e institucional (nacional, europeu e internacional) em que exerce a sua prática profissional. $\mathrm{O}$ debate sobre os regimes de estado-providência nos diferentes países da Europa (Esping-Andersen, 1999 e 2009; Mozzicafredo, 2001; Pereirinha, 1997; Andrade, 2001 e outros), bem como sobre o modelo social europeu (Peneda, 2008; Pereirinha, 2008; outros) possibilita a compreensão da intervenção social no contexto do espaço europeu e contribui para a melhoria das políticas públicas, bem como da formação dos recursos humanos, traduzindo-se, consequentemente, na qualidade da intervenção do assistente social.

Atualmente o assistente social manifesta uma capacidade crítica e um pensamento reflexivo com impactos na responsabilidade social das organizações e na resposta profissional competente e de qualidade aos desafios da sociedade contemporânea marcada pela globalização social. Esta capacidade assenta em três condições: responsabilidade ética; competência técnica e exigência teórica. Capacidade que no período de crise financeira $(2008 / . .$.$) tem sido$ condicionada por medidas de austeridade definidas pelo governo e, no caso português, pelas organizações internacionais (BCE; UE e FMI), exigindo ao assistente social estratégia e criatividade para responder às necessidades de bemestar no quadro dos princípios e valores da sua área de conhecimento: o Serviço Social.

Acrescente-se que a crise dos modelos explicativos da realidade e dos problemas sociais questiona as matrizes teóricas subjacentes à intervenção do Serviço Social. Assiste-se a uma maior exigência ao nível da gestão e da eficácia dos serviços sociais (Banks, 2006). A prática do assistente social tem de assumir uma maior sustentação teórica, tornando-se produtora de ele- 
mentos essenciais à qualificação e requalificação dos quadros metodológicos em Serviço Social. As dimensões axiológicas do Serviço Social têm inflexão nas práticas operativas dos profissionais, dotando-os de maior capacidade crítica face às suas práticas e intervenções, com vista à inovação da resposta social em benefício do cidadão. A metodologia do Serviço Social assume-se como um processo reflexivo resultante do agir profissional e dos testemunhos dos sujeitos, tornando-se facilitadora da construção de conhecimento face aos objetivos de ação desta área de conhecimento.

O Serviço Social tem desenvolvido uma intervenção individual e coletiva, através da aplicação de teorias e metodologias específicas, que lhe permite a organização e planificação de atividades de desenvolvimento social e humano, respeitando a multiculturalidade e a interdisciplinaridade.

\section{O debate académico e científico do Servi- ço Social no quadro das Ciências Sociais}

A formação pós-graduada em Serviço Social e o desenvolvimento desta área de formação em Portugal teve início no final dos anos 80 do sec. XX (1987), com o estabelecimento do convénio científico com a Pontificie Universidade Católica-São Paulo, que promoveu a realização do primeiro curso de mestrado em Serviço Social (1989) e o primeiro programa de doutoramento em Serviço Social (1997). Os doutores e mestres formados no âmbito deste convénio qualificaram o corpo docente em Serviço Social e contribuiram para o aprofundamento do objeto científico desta área de conhecimento, o que contribuiu decisivamente para o reconhecimento da formação em Serviço Social no sistema universitário português pelo Ministério da Educação, com o reconhecimento do grau de licenciatura (1989). Verificou-se ainda uma maior participação do Serviço Social na esfera pública, nomeadamente nos domínios da conceção de políticas sociais, na gestão de programas e projetos sociais; ganhos na qualificação dos profissionais e no plano curricular da licenciatura, nos domínios da teoria, dos modelos de in- tervenção e técnicas de avaliação; a integração na formação inicial da formação de investigação em Serviço Social; a criação de redes internacionais de pesquisa em Serviço Social, como por exemplo a rede Portugal/Brasil.

Em 1995, foi reconhecido o primeiro curso de mestrado em Serviço Social no sistema de ensino superior português, que teve impactos no desenvolvimento da relação de parceria a nível nacional com universidades portuguesas, públicas e privadas, e a nível internacional com a PUC-SP-Brasil e também com a Universidade do Arizona-EUA.

Com o desenvolvimento da formação pósgraduada, o Serviço Social veio ganhar reconhecimento nas diferentes áreas das ciências sociais e humanas e inscrever o seu objeto de estudo nos domínios da investigação e da formação. Os programas de formação pós-graduada produziram desafios para o Serviço Social português, nomeadamente ao nível do desenvolvimento da investigação com a constituição de centros de investigação em Serviço Social ${ }^{4}$.

A produção científica levou ao aumento de publicações e a novos produtos formativos nos domínios da pós-graduação, os cursos de estudos avançados em áreas temáticas e no dominio do pensamento crítico em Serviço Social.

Criou a possibilidade de participação de doutores em Serviço Social nas comissões de decisão e avaliação de cursos de Serviço Social; maior exigência na articulação interdisciplinar nas áreas que constituem o currículo de formação inicial em Serviço Social; enriquecimento dos conteúdos do Serviço Social em matéria de rigor e adequação do objeto no reconhecimento do Serviço Social como área científica. Destacam-se ainda a aprovação de projetos científicos nos domínios do Serviço Social; atribuição de bolsas a mestrandos, doutorandos, pós-doutorandos e investigadores nesta área do saber pela Fundação para a Ciência e Tecnologia, (organismo público de financiamento ao ensino de pesquisa e investigação). Reforço da identidade do Serviço Social como área de conhecimento no domínio das ciências sociais humanas; participação de doutores nas Comissões de Avaliação

${ }^{4}$ Centro Português de Investigação em História e Trabalho Social (CPIHTS); O Centro de Investigação em Ciências do Serviço Social (CICSS); O Centro Lusíada de investigação em Serviço Social e Intervenção Social (CLISSIS) da Universidade Lusíada de Lisboa; e o Centro de Investigação e Estudos de Sociologia (CIES) do ISCTE-Instituto Universitário de Lisboa. 
do Ensino Superior do sistema universitário português.

O reconhecimento do grau de Doutor em Serviço Social garantiu maior autonomia, participação e decisão do Serviço Social no sistema universitário, com influências positivas e directas na profissão e também nas entidades empregadoras e nas entidades promotoras de políticas sociais.

Outro marco significativo foi a integração do Serviço Social nos programas comunitários (pós adesão de Portugal à Comunidade Económica Europeia 1986) do ensino superior: o programa Sócrates/Erasmus e Leonardo da Vinci. Esta mobilidade promoveu a troca de experiências académicas, científicas e profissionais, a promoção de redes de pesquisa e estudo e o alargamento do âmbito de pesquisa em Serviço Social. Todo este processo evolutivo da qualificação em Serviço Social possibilitou o desenvolvimento da rede tecnológica, a absorção da internet e o campus virtual.

Atualmente existem em Portugal três programas de Doutoramento em Serviço Social: no ISCTE-Instituto Universitário de Lisboa (Público), na Universidade Católica Portuguesa (ensino concordatário) e na Universidade Lusiada de Lisboa (Privado).

\section{Princípios e valores do Serviço Social con- temporâneo}

O Serviço Social embora realize formação pósgraduada desde a última década do seculo XX, continua a utilizar os quadros teóricos das ciências sociais e humanas, integrando pouco nos seus planos formativos o conhecimento produzido pela investigação nesta área de saber. Por tradição, o assistente social desenvolve a sua intervenção baseada na relação de ajuda psicossocial personalizada, orientada por quatro ordens de valores ou sejam, os valores Humanistas, que centram a sua atenção no Homem e no respeito de si mesmo; os valores Democráticos que desenvolvem as condições necessárias ao desenvolvimento da sua personalidade e a sua participação social e cívica na sociedade; os valores Políticos e os valores Económicos, que promovem o princípio da subsidiariedade e da igualdade de oportunidades e de direitos sociais e os valores educativos sustentados na dimensão científica do saber, nos quais o profissional se apoia e fundamenta o seu plano de intervenção.
A incorporação destes valores na prática do assistente social requer dos planos de formação em Serviço Social o aprofundamento do conhecimento da Ética como referencial teórico e deontológico, que não se restringe aos códigos de ética ou a princípios deontológicos, mas que apela à compreensão conceptual e à sua operacionalização na intervenção profissional no quadro da complexidade social que envolve as políticas, as pessoas, o contexto social, cultural e comunitário.

A evolução ética e deontológica da profissão na atualidade, (...), postula um novo humanismo: o humanismo social, baseado sobre a ética da convicção (...), a ética da responsabilidade - que inclui para além dos objetivos a análise dos meios, das diferentes opções e a avaliação das suas consequências, assim como a nossa capacidade empática, e a ética da discussão, que supõe a elaboração coletiva, a partir da livre discussão entre pessoas implicadas, e que inclui ter de partilhar, elaborar, decidir em relação a projetos comuns, com todo o que significa de negociação, concessões, e acordos (Robertis, 2003, p. 11).

No domínio ético o profissional deve saber respeitar e usar na sua intervenção os princípios de singularidade, de liberdade e autodeterminação de cada cidadão, o respeito de intimidade e à vida privada do sujeito, a autonomia da pessoa, reconhecendo-lhe competências e capacidades, e de interdependência face aos direitos e deveres que são reconhecidos a todo o Cidadão em sociedade. É também importante realçar a ética da responsabilidade social e a ética da comunicação.

A Ética é uma disciplina que desafia o Agir Humano, cuja tarefa essencial é fornecer os fundamentos que orientam a ação e capazes de captarem no próprio agir político (na sua dimensão de processo ético-político) as diretrizes deontológicas que se constituem como elementos básicos da profissão na sua prática quotidiana.

A sociedade atual, marcada pela era da globalização procura na ética o desafio à participação no debate contemporâneo sobre as manifestações da nova questão social, bem como os efeitos desta no processo ético. Segundo Ferreira (2011a., p. 205),

A ética deve evitar que a conduta profissional se transforme apenas numa declaração de boas intenções, mas sim que a conduta profissional as- 
suma a sua responsabilidade cívica e política, com o objetivo da construção de propostas coletivas alternativas aos problemas sociais atuais.

A filosofia atual que norteia a noção de bem-estar social baseia-se em princípios de cidadania, participação e responsabilidade partilhada, o que promove a construção dos pressupostos e fundamentos éticos para a organização das práticas sociais e estabelece em simultâneo uma relação de controlo que, por vezes, é facilitadora da intervenção profissional dos assistentes sociais e, noutras, limita a sua atuação.

\section{Segundo Serafim}

A ação do assistente social, no quadro da determinação dos direitos humanos, políticos e sociais implica que se tenha presente a emergência de novas formas de ação social contextualizadas pela valorização do local e das dinâmicas territoriais, suportadas pela importância crescente das redes e pela generalização das novas tecnologias de comunicação e informação (2001, p. 91).

Presentemente, integramos e partilhamos um debate europeu em que o conhecimento ocupa lugar de destaque, com vista a uma maior consolidação e fundamentação teórica suportada na investigação enquanto geradora do respetivo conhecimento e que o valida.

Ao Serviço Social, neste início do século XXI, propõe-se como desafio o aprofundamento de quadros teóricos e metodológicos que estimulem uma intervenção profissional centrada nas competências do cidadão enquanto ser humano capaz de construir o seu próprio percurso de vida, no âmbito da construção de uma cidadania social plena e participativa. A profissão tem como suporte um conjunto instrumental de métodos e técnicas que intervêm como dispositivos metodológicos de ação social. O assistente social no exercício da sua atividade identifica dois tipos de competências técnicas e teóricas. Ao nível das competências técnicas destacamse na formação do assistente social as seguintes: «conceção, relação, comunicação, intervenção e avaliação sendo esta a menos exercitada pelos profissionais e a mais necessária». No que respeita às competências teóricas, os assistentes sociais revelam na sua prática o domínio do conhecimento em Serviço Social ao nível do: «saber-fazer, saber-ser/ estar, respeito, autodeterminação, não fazer juízos de valor (Empo- werment), elaboração do diagnóstico social» (Ferreira, 2011, p. 208). Importa ainda reforçar as competências sociais necessárias à sua dimensão comunitária e de proximidade, exigindo a este profissional um conhecimento acrescido da realidade macro, micro e meso sobre o território onde desenvolve a sua prática profissional.

A complexidade das situações sociais em que o Serviço Social é chamado a intervir na sociedade contemporânea, apresenta como necessidade um suporte teórico e metodológico baseado em ferramentas de trabalho qualitativas, participativas e proactivas, colocando a centralidade da intervenção social no domínio da intersubjetividade.

Ainda ao nível das competências técnicas do Serviço Social o assistente social para além de utilizar na intervenção um conjunto de dispositivos operativos das políticas sociais (ferramentas), desempenha um conjunto de funções especializadas no domínio do diagnóstico, do planeamento e da resposta social que exigem do profissional uma capacidade e competência de conceção e estratégia para conciliar com eficácia uma resposta ao problema no contexto institucional em que se insere, no quadro das políticas sociais e dos direitos sociais do beneficiário da ação.

Ao nível das práticas, o assistente social desenvolve uma intervenção individual, coletiva e comunitária fundada nos princípios da interdisciplinaridade, da intervenção em rede e da promoção da cidadania social ativa junto da criança e da família (idem).

\section{Impactos e dinâmicas profissionais}

O Serviço Social sendo uma área de conhecimento interdisciplinar, generalista na sua formação que intervém em diferentes problemas sociais, possibilita a intervenção em diferentes áreas e desenvolve diferentes abordagens teóricas e metodológicas, numa relação interativa entre conhecimentos teóricos, conhecimentos metodológicos e instrumentais e conhecimentos empíricos. O Serviço Social é permanentemente confrontado com a pressão da resolução de problemas reais, que afetam indivíduos/populações e que influenciam o funcionamento da sociedade.

Atualmente, o Serviço Social procura clarificar através do processo de investigação alguns equívocos, nomeadamente: a confusão entre teorias e os modelos de caso, grupo e comunida- 
de que suportam teoricamente a ação do Serviço Social (Amaro, 2012).

Se o Assistente Social quer atuar de forma competente e útil nas situações práticas necessita ter conhecimentos do que é que está acontecer e porquê, o qual significa que necessita pensar teoricamente. Se não o fizer a intervenção social converte-se numa forma de puzzle desorganizado de experiências, que tem como resultado final, uma prática espontânea (Viscarret, 2008, p. 20).

A formação pós-graduada, em especial os programas doutorais em Serviço Social, tem por missão contribuir significativamente para a clarificação do objeto científico, profissional e teórico do Serviço Social. O resultado de um programa doutoral identifica-se através de um processo de investigação sustentado em métodos e técnicas que orientam o exercício de uma tese original que trata um objeto de estudo de um campo de saber específico. Exige clareza no objeto de estudo, requer a construção de um quadro teórico adequado e aplicável ao objeto de estudo, obriga à definição de uma metodologia científica potenciadora na recolha e sistematização de informação sobre esse objecto e promotora de novo conhecimento. Assim, a construção do objeto de estudo em Serviço Social tem de integrar: o domínio do Serviço Social; a dimensão interdisciplinar do objeto; o quadro individual e coletivo; o contexto institucional, politico e comunitário e a abrangência do objeto de investigação: complexidade, grandeza e dimensão nacional e internacional.

O Serviço Social na contemporaneidade exige uma formação pós-graduada que vise a especialização em campos específicos de atuação do assistente social. Segundo Sheppard, (1995), quando valoramos a importância de um determinado conhecimento para o Serviço Social, não podemos ter apenas em conta a sua validade teórica, segundo a qual um conhecimento é válido em termos epistemológicos e metodológicos, mas deve-se ter também em conta a sua validade prática, referindo-se à consistência e satisfação do objetivo e dos propósitos do Serviço Social.

Neste quadro de reflexão, a formação em Serviço Social apresenta-se como um processo sistemático de estudos avançados no domínio específico do Serviço Social, promotores de construção teórica e metodológica e ampliação do quadro científico desta área do conhecimento ao nível da análise e da interpretação, diminuindo o seu nível descritivo. O Serviço Social Clássico suportava-se numa praxis do conhecimento baseado na realidade social que desenvolvia a sua ação através da observação e registo, criando uma identidade da profissão para a intervenção e descrição dos problemas sociais. Passado o período da modernidade e pós-modernidade e com o avanço da investigação em ciências sociais, o Serviço Social enriqueceu o seu conhecimento técnico e teórico, com o aprofundamento dos métodos qualitativos e quantitativos aplicados às ciências sociais, reconfigurando uma nova identidade profissional mais identificada com uma profissão com saber teórico e cientifico e com domínio analítico e interpretativo da realidade social capacitado para influenciar e contribuir para a melhoria das políticas de bem-estar social.

Se o papel das teorias no Serviço Social é o de orientar, procurar e construir conhecimentos conduzidos crítica e reflexivamente, não se esgota neste domínio e constitui-se como pedra de toque da construção da identidade profissional, entendida como a busca de uma racionalidade crítica e reflexiva que permita a construção epistemológica do que lhe é próprio e específico». (Restrepo, 2003, pp. 21-45). Também Stepney refere, ««prática-teórica» é um aspeto central da profissão de assistente social. A leitura da prática é feita com base em orientações teóricas, embora com um objetivo comum, encontrar hipótese que expliquem e predizem certos tipos de intervenção e que visam obter determinados resultados ao nível da pessoa, do comportamento, da rede social e outras. É uma forma de organização «mental» do conhecimento que posteriormente define e orienta os métodos e técnicas a utilizar pelo profissional (Stepney, 2000, p. 21).

Com o desenvolvimento e aprofundamento da investigação em Serviço Social a construção da teoria em Serviço Social passa a suportar-se em leis e valores que reforçam a confiança e o debate teórico/científico no quadro das ciências Sociais e Humanas, obrigando todas as áreas científicas a definir melhor as suas fronteiras e a saber reconhecer e respeitar os campos e domínios de cada uma, reforçando a autonomia do Serviço Social.

As teorias científicas são constituídas por leis e princípios que dão uma explicação univer- 
sal de um campo alargado de fenómenos através de generalizações empíricas. A teoria constróise através de preposições de grande nível de abstração, generalização e de explicação e predição. Segundo Rudner, as características estruturais das teorias sociais são as mesmas de qualquer outra teoria científica, constituída por «um conjunto de leis sistematicamente relacionadas constituem uma teoria científica». (Rudner, 1966, p. 29).

Em Serviço Social é urgente e importante desenvolver investigação que contribua para a construção da sua teoria, definindo assim um modelo teórico e uma hipótese teórica, afastando-se da sua matriz tradicional e mais conservadora sustentada em modelos análogos. Conhecimento científico que deve ser integrado tanto nos planos de formação graduada e pós-graduada em Serviço Social como nas práticas profissionais do assistente social, prevenindo assim a sua desprofissionalização.

No processo de construção teórica o investigador tem de integrar Valores (princípios da filosofia orientadores da profissão, Direitos $\mathrm{Hu}-$ manos); o domínio da disciplina científico (o conhecimento como área de saber) e o conjunto dos elementos que constroem a forma de pensar a pessoa.

A construção teórica em Serviço Social deve, de acordo com a minha reflexão, integrar no seu debate:

- A Perspetiva Positivista, baseada no conhecimento e na objetividade e que tem por objetivos a explicação e a predição dos fenómenos;

- A Perspetiva Interpretativa, baseada no conhecimento, na interpretação de natureza relativista e reflexiva do contexto em que ocorre e que integra os meios e os recursos disponíveis;

- A Perspetiva Crítica, baseada no conhecimento (a verdade impõe-se à configuração do conhecimento como controlo). São teorias pluralistas que privilegiam o poder do sistema e tem como objetivos a emancipação e o empoderamento de grupos vulneráveis.

O processo de construção teórica em Serviço Social é uma sistematização de conceitos e relações e é uma forma sistemática de narrar proposições testadas no campo empírico. Assim, esta construção teórica integra: Conceitos;
Relação entre conceitos; Proposições; Relação entre proposições; Correlação entre proposições e campo empírico da observação e produção de dados.

De acordo com White e Klein (2008), a teoria científica nasce na rede complexa do espaço social, da observação baseada em regras que orientam a interpretação. Se o resultado for apenas uma explicação do observado, não é Teoria. Porque apenas define categorias, tipologias, ou estabelece relação entre variáveis. A orientação dedutiva descreve de forma simples, numa tentativa de aumentar a compreensão do Homem, de forma a promover explicações sobre o que se estuda e ou observa. Na construção teórica em Serviço Social ganha relevância a dimensão indutiva caraterizada por generalizações a partir do campo empírico, que permitem construir e ou desenvolver a teoria. Importa ainda realçar que a investigação em Serviço Social parte já de uma teoria, acentuando-se a prática dedutiva, embora reconheçamos que para uma efetiva construção teórica é necessário aplicar quer o método dedutivo, quer o indutivo, na construção da teoria.

$\mathrm{Na}$ actualidade, o Serviço Social procura no processo de investigação argumentos teóricos e científicos que ganhem força política no debate interdisciplinar das ciências sociais, retirando-o de uma posição subalterna e fortalecendo-o como área de conhecimento e como profissão no quadro dos princípios, valores e fundamentos do Serviço Social. Segundo Bisman (1999), a teoria em Serviço Social não pode ser comprovada em laboratório, porque a prática do assistente social realiza-se com baixas condições de comprovação, pois a prática desenvolve-se geralmente no meio do caos e dos problemas.

A produção do conhecimento, segundo $\mathrm{Fe}$ rreira (2011), orienta o Serviço Social em dois níveis de ação:

- A intervenção Assistencialista, que procura corrigir uma disfuncionalidade através da utilização de recursos sociais e comunitários, aliviar as necessidades, limitações e alterar os fatores promotores de situações problemáticas e de mal-estar social (mundo individual da pessoa);

- A intervenção promotora de autonomia, que procura reduzir as diferenças existentes entre a capacidade natural de resposta ou de 
funcionalidade social dos indivíduos na resposta às suas situações problemáticas, atendendo à sua realização pessoal e progresso social (mundo exterior).

De acordo com Healy, (2001), é necessário recriar o Serviço Social crítico, integrando aspetos das teorias pós-estruturalistas do Serviço Social, que surgiram, com mais enfoque, a partir dos anos 90 do Séc. XX. A teoria Crítica centra as suas propostas analíticas no desafio à dominação e opressão sob todas as suas formas (estrutural, interpessoal e pessoal); na ideia de que as estruturas sociais são construídas e, nesse sentido, mutáveis; na crítica profunda à abordagem positivista, que apela ao determinismo e à passividade individual, e na necessidade de encontrar novas fontes de conhecimento (Fook, 2002).

Neste quadro teórico identificamos o Serviço Social Crítico, que bebe das correntes construtivistas da teoria social, podendo mesmo centrar as suas conceções neste predicado. É, naturalmente, neste contexto que se inscreve o Serviço Social Construtivista proposto por Parton (1996) e neste âmbito, a prática reflexiva que, mais do que visar a constituição de um conhecimento estabilizado, pretende o desenvolvimento das capacidades de reflexividade e de ação, tendo em vista o engajamento entre as nossas verdades, histórias e construções e as dos outros. Perante a impossibilidade de propor projetos coletivos que não sejam utópicos e violentadores da individualidade de cada sujeito, o Serviço Social Crítico apresenta-se, também, como uma proposta pragmática para a intervenção do assistente social.

\section{Conclusões}

O assistente social é na atualidade um profissional que precisa de uma formação Humana, que lhe permita estabelecer uma relação com o sujeito; uma formação Teórica, que lhe permita organizar um plano de intervenção ajustado ao problema da pessoa, da comunidade e facilite um discurso interdisciplinar com outros atores e saberes intervenientes no problema; e uma formação Técnica na utilização de metodologias adequadas e eficazes na resposta ao problema do Sujeito e que desenvolva a sua cidadania ativa através da capacitação e empowerment das competências pessoais, sociais, interpessoais, relacionais e laborais. È também um cientista social que necessita de conhecimento científico não apenas sustentado em teorias e modelos de intervenção, mas essencialmente de conhecimentos, de metodologias de pesquisa e de métodos quantitativos e qualitativos que lhe permitam analisar, interpretar e fazer propostas de desenvolvimento social e humano no contexto do debate político, profissional e cientifico.

O Serviço Social hoje tem de preparar um profissional capacitado para acompanhar a mudança do modelo de estado e sociedade. Segundo James (1986),

In seeking to understand the impact of a neoliberal approach on social work practice it is important for us to reflect on the uniqueness of social work which is not due to a discrete knowledge base, but rather its perspective on people's problems in «living» and therefore ' $(. .$.$) the$ inter-connectedness and interdependence of individuals with their society, believing that «private troubles» and «public issues» are intimately related. The knowledge base, therefore, is derived from research about individuals and society and, more importantly, about the dynamic relationship between the two. (James, in Spolander et al., 2014, p. 305).

A declaração de Bolonha tem produzido alterações significativas no paradigma de ensino superior, reforçando a mobilidade, a flexibilidade e a comparabilidade, baseado no sistema de transferência de créditos europeu (ECTS), tendo em vista a promoção da empregabilidade, e a promoção da coesão europeia, através do conhecimento e da inovação, num espaço europeu competitivo. Este modelo que integra também a formação em Serviço Social é concretizado pelo desenvolvimento de um novo quadro organizativo do ensino superior, centrado no aluno e nos objetivos da formação, embora se verifiquem problemas dada a diversidade de planos de formação aos níveis nacional e europeu. A nível nacional e europeu os planos de estudo apresentam pouca uniformidade na duração da formação (6, 7 e 8 semestres) e as unidades curriculares apresentam ECTS diferenciados que impedem ou dificultam os objetivos de Bolonha respeitantes à mobilidade e internacionalização da formação.

$\mathrm{Na}$ última década as instituições de ensino superior ganharam novos campos no domínio 
do saber e do conhecimento, nomeadamente: emprendedorismo, inovação, excelência, mérito, criatividade, flexibilidade e a capacidade em gerir o risco. No entanto, o Serviço Social continua a apresentar um défice no debate científico na academia, o que tem possibilitado alguma desvirtualização da formação em Serviço Social com consequências na qualidade das práticas profissionais do assistente social. Segundo Spolander e outros,

The challenges of limited resources or insufficient resources to meet demand, has not only resulted in increased emphasis on risk-based approaches but these have been at the detriment of prevention, along with attacks on universal social work services due to the concerns about efficiency, risk and prioritization (Hojer and Forkby, 2010; Holscher, 2008, in Spolander et al., 2014, p. 306).

O processo de formação em Serviço Social deve acompanhar as tendências atuais da sociedade globalizada, preparando os profissionais para a conceção, diagnóstico, intervenção, avaliação e investigação das novas questões sociais na sociedade contemporânea, integrando-se assim no pensamento internacional do Serviço Social: Evidence based practice in Social Work e Research based practice in Social Work.

O Modelo de Formação Prática em Serviço Social no quadro do Plano de Formação de Bolonha estabelece um conjunto de relações de ensino-aprendizagem no domínio da formação, centradas no aluno e no desenvolvimento das suas capacidades.

O Serviço Social enfrenta um novo desafio, ou seja, o da investigação em Serviço Social com vista à problematização das questões (problemas) sociais atuais, tendo como meta a potenciação de competências teórico-operativas e investigativas para o exercício profissional do assistente social. A este desafio está associada a tradição da formação em Serviço Social caraterizada por uma forte componente prática (próxima do modelo clínico) que deve continuar a ser valorizada e defendida no debate académico de forma a dar a esta formação a sua singularidade no quadro das ciências Sociais e Humanas. Defendo um modelo de formação prática em articulação efetiva com as organizações sociais da sociedade civil (Públicas e Privadas) nas diferentes áreas da Ação Social.
É necessário e urgente iniciar uma reflexão aprofundada ao nível da formação em Serviço Social no quadro do contexto social, político e económico e definir com maior rigor o papel da formação prática tanto no plano de formação como no plano da certificação de um estudante de Serviço Social para o exercício da profissão de assistente social. É necessário reforçar o diálogo e o compromisso entre a Universidade, o Assistente Social e a Organização/instituição acolhedora do estágio. $\mathrm{O}$ supervisor institucional tem de ser reconhecido na universidade como um ator de formação prática em Serviço Social que tutoria, orienta e acompanha o progresso da aplicação de conhecimentos teóricos do estagiário no exercício profissional. $\mathrm{O}$ assistente social e a organização/instituição acolhedora do estágio tem de reconhecer o papel da universidade no aprofundamento de quadros teóricos e metodológico através da investigação, estabelecendo relações de parceria qualificadas e de mais-valia para ambas as partes e para a formação e profissão.

Num processo de formação curta como se carateriza o atual processo de Bolonha, em áreas de formação que intervêm com a pessoa humana e que tomam como quadro estruturante os direitos humanos, a formação prática articulada com o exercício profissional pode ser inovado e no caso particular o Serviço Social sempre foi e é pioneiro neste modelo articulado entre teoria e prática.

A sociedade contemporânea apela à desconstrução de estereótipos na formação em Serviço Social, nomeadamente na flexibilidade da conciliação do Estudo com o Trabalho, devendo ser explorada a possibilidade do estágio curricular no posto de trabalho, sempre que reúna as condições pedagógicas adequadas e garanta uma formação de qualidade em Serviço Social. Promover junto das equipas de Serviço Social nas Organizações a dinamização de unidades de excelência de formação prática protocolados com as instituições de ensino superior, possibilitando a organização e desenvolvimento dos grupos de reflexividade sobre a prática profissional, aliando intervenção e investigação. Integrar na análise, reflexão, debate científico e profissional o contexto internacional social, económico, cultural e político. «The challenge to interpret social work from an international 
perspective requires an understanding of practice context and to view this beyond state welfare provision» (Spolander et al., 2014, p.303)

No atual contexto da organização do Ensino Superior a formação em Serviço Social exige a formalização de um novo compromisso com as
Organizações Sociais (publicas, privadas e de solidariedade social), para a qualidade da qualificação, o reforço da identidade profissional e prevenir a sua descaraterização no quadro das Ciências Sociais e Humanas.

Estratégia de Lisboa,2000.

\section{Referências}

Amaro, Inês (2012). Urgências e Emergências do Serviço Social. Lisboa: UCP.

Andrade, Marília. (2001 a) Serviço Social e Mutações do Agir na Modernidade. Tese de doutoramento. São Paulo: Ed. PUC/SP.

Banks, Sarah (2006). Ethics and values in social work (3rd ed), Palgrave.

Bisman, Cynthia D. (1999). Social Work Assessment: Case Theory Construction. Families in Society $80,240-246$.

Esping-Andersen (2009). Incomplete Revolution: Adapting Welfare States to Women's New Roles. Cambridge UK: Polity Press.

Esping-Andersen (1999). Social Foundations of Postindustrial Economies. ISBN 0198742002, 9780198742005. Oxford University Press.

Ferreira, Jorge M. L. (2011a.). Serviço Social e Modelos de Bem-Estar para a Infância. Modus Operandi do Assistente Social na Promoção da Protecção à Criança e à Familia. Lisboa: Ed Quid Juris.

Ferreira, Jorge M. L. (2011b.) Contributos para o Debate da Epistemologia em Serviço Social. In Global Social Work Journal of Social Intervention Research-Trabajo Social Global Revista de investigaciones en intervención social, 2 (3). Disponível em: http://tsghipatiaeditorial.com/index.php/tsg1/article/view/32

Ferreira, Jorge M. L. (2009). Pensar a formação em Serviço Social no quadro da globalização e do Espaço Único Europeu. Revista Intervenção Social, 35,350-366 «O Serviço Social no Século XXI: desafios e oportunidades», do Instituto Superior de Serviço Social - Universidade Lusíada Lisboa.

Ferreira, Jorge M. L. (2008). Trajetórias e Produção do Conhecimento do Serviço Social Português. O Papel do Instituto Superior Serviço Social de Lisboa - ISSSL. Revista Intervenção Social, 32/34 da Universidade Lusíada - Instituto Superior de Serviço Social de Lisboa.

Fook, Jan (2002). Social Work. Critical Theory and Practice. London: Sage Publ.

Healy, Karen (2001). Trabajo Social: perspectivas contempráneas, Madrid e Corunha: Ediciones Morata e Fundación Paideia.

Mozzicafreddo, Juan P. (2001). Cidadania e administração pública em Portugal. In Administração e política A reforma da administração pública na Europa e nos Estados Unidos, pp.145 - 157. João Salis Gomes:ed. Juan Mozzicafreddo; Oeiras: Celta.

White, James M. and Klein, David. M. (2008). Family theories. $3^{\text {a }}$ ed. London: Sage Publication, Ltd. ISBN: 978-1-4129 -3748-1.

Parton, N. (1996). Social Theories, Social change and Social Work: Towards a new practice. Londron: Macmillan Press.

Peneda, José A. Silva (2008). Modelo Social Europeu. ¿Qué futuro? Porto: Porto editor.

Pereirinha, José. A. (1997). États-providence et dispositifs de lutte contre la pauvreté - quelques éléments pour une comparaison axée sur les pays d'Europe du Sud. Le cas spécifique du Portugal. Comparer les systèmes de protection sociale en Europe du Sud (pp. 517-556). Paris: MIRE,. London: Bruno Palier (ed).

Pereirinha, José. A. (2008). Politica Social. Formas de Actuação no Contexto Europeu. Lisboa: Ed. Universidade Aberta.

Restrepo, Olga Lúcia Vélez (2003). Reconfigurando el trabajo social. Perspectivas y tendências contemporaneas. Editorial Espacio. Buenos Aires.

Robertis, Cristina (2003). Fundamentos del trabajo social, ética e metodología. Valência: PUV Publications, Nau Librés, Universitat Valência. 
Rudner, R.S. (1980). Filosofia de la ciência social. Madrid: Ed. Alianza.

Sheppard, M. (1995). Social Work, Social Science and practice wisdom. British Journal of Social Work, 25.

Spolander, Gary, et al. (2014). The implications of neoliberalism for social work: Reflections from a six-country. International research collaboration. http://isw.sagepub.com/content/57/4/301

http://www.sagepublications.com.

Stepney, P. et al. (2000). Social Work Models, Methods, and theories. Dorset Russel: House Publi0shing.

Serafim, Maria Rosário. (2001) O Local em Rede: novos horizontes param o Serviço Social (pp. 91107). In Estudos do Serviço Social Brasil e Portugal. São Paulo/Brasil: Ed. Educação.

Viscarret, Juan Jesús (2009). Modelos y métodos de intervención en Trabajo Social. Madrid:. Editora Alianza Editorial.

Carta Social Europeia.

Decreto - Lei n ${ }^{\circ} 74 / 2006$, de 24 de março.

Decreto - Lei $n^{\circ} 115 / 2013$ de 7 de agosto.

Declaração Universal dos Direitos do Homem, ONU, 1948. 